\title{
GRANULAÇÃO CROSTOSA EXUBERANTE EM TERAPÊUTICA COM ISOTRETINOINA ORAL: RELATO DE CASO
}

\author{
CRUSHY EXUBERANT GRANULATION IN THERAPEUTIC WITH \\ ORAL ISOTRETINOIN: CASE REPORT
}

Maria Beatriz Gomes Castro ${ }^{1}$ Lívio Vasconcelos do Egypto ${ }^{2}$

RESUMO: Objetivo: o objetivo deste trabalho é demonstrar o curso clínico de um paciente com granulação crostosa exuberante após tratamento de acne nódulocística com isotretinoina oral. Método: Trata-se de um relato de caso, um estudo observacional, com caráter descritivo e abordagem qualitativa. $O$ estudo foi realizado na Clínica Neurederm serviços médicos LTDA no período de outubro e novembro de 2020. A amostra foi composta por um paciente, masculino, 20 anos, previamente hígido, portador de acne grau IV e com disgnóstico de granulação crostosa exuberante pelo uso de isotretinoína oral. As informações foram extraídas de um prontuário eletrônico, com ênfase no exame clínico, tratamento e evolução clinica do paciente. Resultados: $O$ paciente retratado no caso clínico em questão, apresentava acne nódulo-cística há 6 meses a qual foi tratada inicialmente com isotretinoina oral com progressão para tecido de granulação exuberante em face e dorso, sem sintomas sistêmicos. Assim, foi realizada a suspensão da isotretinoina oral e inicio de um tratamento de ataque com corticoterapia e antibioticoterapia por via oral e manutenção por via tópica até a resolução completa das lesões que ocorreu em 8 meses do inicio do tratamento. Conclusão: Dessa forma, tendo em vista a precariedade de estudos a cerca do assunto abordado, se faz necessário novos estudos com pacientes que desenvolveram essa patologia para auxiliar os profissionais médicos na escolha do melhor tratamento segundo nível de evidência disponível. Com uma melhor compreensão da doença, é possível que sejam desenvolvidas e direcionadas ações específicas para o manejo dessa enfermidade.

Descritores: Acne; Isotretinoina; Tecido de Granulação.

\footnotetext{
${ }^{1}$ Graduanda em Medicina no Centro Universitário de Patos (UNIFIP), Paraíba.

${ }^{2}$ Médico Dermatologista pela Universitade. Docente do Curso de Medicina do Centro Universitário de Patos (UNIFIP), Paraíba.
} 
ABSTRACT: Objective: the objective of this work is to demonstrate the clinical course of a patient with exuberant crusted granulation after treatment of nodularcystic acne with oral isotretinoin. Method: This is a case report, an observational study, with a descriptive character and a qualitative approach. The study was carried out at Clínica Neurederm Serviços Médicos LTDA between October and November 2020. The sample consisted of a male patient, 20 years old, previously healthy, with acne grade IV and with a diagnosis of exuberant crusted granulation due to the use of oral isotretinoin. The information was extracted from an electronic medical record, with emphasis on clinical examination, treatment and clinical evolution. Results: The patient portrayed in the clinical case in question, had nodular-cystic acne for 6 months which was initially treated with oral isotretinoin with progression to exuberant granulation tissue on the face and back, without systemic symptoms. Thus, the suspension of oral isotretinoin was carried out and an attack treatment was started with corticotherapy and antibiotic therapy oral and maintenance by topical route until the complete resolution of the lesions that occurred in 8 months. Conclusion: Thus, in view of the precariousness of studies on the subject addressed, it is necessary to conduct further studies with patients who developed this pathology to assist medical professionals in choosing the best treatment according to the level of evidence available. With a better understanding of the disease, it is possible that specific actions are developed and directed to the management of this disease.

Keywords: Acne; Isotretinoin; Granulation tissue. 


\section{INTRODUÇÃO}

A acne é uma dermatose inflamatória crônica, caracterizada pelo acometimento da unidade pilossebácea, geralmente autolimitada, promovendo a formação de pústulas, pápulas, comedões, e, menos frequentemente, por nódulos ou pseudocistos. Predominantemente em jovens, surge durante a puberdade, podendo surgir a partir dos 11 anos de idade, aumentando a prevalência caso exista histórico familiar (BRITO et al., 2010).

Até 1940 não existia tratamento efetivo contra acne, ultilizava-se medicamentos tópicos ineficazes. Os tratamentos convencionais tópicos e sistêmicos são eficazes e melhoram as lesões. Contudo, a instrução do tratamento de isotretinoína oral revolucionou o manejo da acne (BIESKI, 2016).

A isotretinoína é um tipo de retinóide derivado sintético da vitamina A (retinol), a qual foi sintetizada em 1955 e utilizada pela primeira vez em 1976 na Europa e em 1980 nos EUA para o tratamento de acne grave. No Brasil, foi introduzida desde 1982, onde desde então tem sido amplamente utilizado para o tratamento tópico e sistêmico de várias dermatoses. Os retinóides agem na lesão primaria: o microcomedo, atuam no crescimento e diferenciação das células epidérmicas, assim como tem propriedades imunomoduladoras e antiinflamatórias, além de interferir na atividade da glândula sebácea (RIVITTI, 2014).

As indicações convencionais do tratamento com isotretinoína oral são: acne nódulo-cística e acne resistente ao tratamento convencional (graus III e IV). Sendo a dose diária calculada de acordo com o peso do paciente e varia de 0,5 a 1,0mg/kg (BRITO, 2010).

A isotretinoína oral pode causar inúmeros efeitos colaterais e tem grande potencial teratogênico. Esses efeitos são divididos em dois grupos: efeitos mucocutâneos e efeitos tóxicos sistêmicos. Dessa forma, o tratamento pra acne deve ser indicado aos casos mais graves e quando há resistência a outras terapias (SILVA JÚNIOR et al., 2009). 
As alterações nas membranas mucosas e pele são decorrentes da diminuição da produção de sebo, redução da espessura do estrato córneo e alteração da função de barreira da pele. A maioria dos pacientes desenvolve ressecamento e fissura de lábios, pele e mucosas. Onde geralmente são controlados com hidratantes labiais e antibióticos ou antifúngicos, se necessário, sendo desnecessária a suspensão do medicamento (RIVITTI, 2014).

Podem ocorrer infecções cutâneas por S. aureus, por conta do aumento da sua colonização, decorrente a redução da produção do sebo pelo medicamento. A fotossensibilidade pode ocorrer em ate $40 \%$ dos casos, por conta da diminuição das camadas do estrato córneo (FEILY et al., 2020).

A formação de tecido de granulação exuberante é uma outra complicação rara do tratamento com isotretinoína oral que consiste em uma neoformação de tecido colagenoso frouxo edemaciado de maneira disfuncional. Essa alteração tecidual impede o reparo adequado das lesões de acne prévias, podendo ainda, complicar com infecção secundária local, caracterizando-o como granuloma piogênico (FIGUEIRAS et al., 2016).

Essa reação adversa ocorre mesmo com baixas doses terapêuticas de isotretinoína oral e implicam em prejuízo significante na qualidade de vida do paciente, sendo, algumas dessas injúrias, resistentes a suspensão do retinóide oral. Nesses casos, faz-se necessária a aplicação de outras terapias como corticoesteróides tópicos de alta potência, coagulantes tópicos, cauterizações, laserterapias e, até mesmo, excisões cirúrgicas (FRIEDLANDER, 1998).

Devido a baixa incidência da granulação crostosa ao uso do retinóide oral, foi observada a necessidade de abranger em estudo a avaliação e análise do caso em questão. Sendo assim, o objetivo deste trabalho é demonstrar o curso clínico de um paciente com granulação crostosa exuberante após tratamento de acne nódulocística com isotretinoina oral. 


\section{METODOLOGIA}

A investigação do estudo será conduzida através de um relato de caso, um estudo observacional, com caráter descritivo e abordagem qualitativa. O objetivo do relato de caso é descrever detalhadamente determinada realidade por seu aspecto singular e é tradicionalmente utilizado na área da saúde, podendo ser utilizado, ainda, para fornecer informações fundamentais para a melhor decisão na conduta clínica. Dessa forma, por possuir caráter essencialmente descritivo, este estudo tem como finalidade retratar a realidade, assim como, disponibiliza dados demográficos relevantes para gestores e profissionais de saúde (ARAGÃO; 2011).

O relato de caso é uma ferramenta bastante útil para retratar a descrição detalhada de casos clínicos, por conter peculiaridades relevantes sobre os sinais e sintomas do paciente, além de outras características particulares do mesmo. Nesse tipo de metodologia científica, a conduta terapêutica e a evolução clínica do paciente devem ser descritas de forma específica para auxiliar o seguimento de futuros casos por outros profissionais. Isso ocorre, por descreverem de forma clara em condições e doenças raras em que seus diagnósticos e tratamentos não estão claramente definidos na literatura científica (OLIVEIRA et al. 2016).

O estudo minucioso do caso foi realizado na Clínica Neurederm serviços médicos LTDA no período de outubro e novembro de 2020. O sujeito, escolhido para o caso, possuiu as seguintes características: masculino, 20 anos, estudante, portador de acne grau IV e com disgnóstico de granulação crostosa exuberante pelo uso de isotretinoína oral. Após a aprovação pelo Comitê de Ética e Pesquisa (CEP) do Centro Universitário de Patos - UNIFIP, número do parecer e número do $\mathrm{CAE}$ 37454620.0.0000.5181, o paciente foi convocado e esclarecido sobre a pesquisa e seu objetivo com posterior assinatura do Termo de Consentimento Livre e Esclarecido (TCLE) e o termo de assentimento. Com isso, os trâmites que envolvem a referida pesquisa foram realizados conforme as normas da resolução 510/16 do Conselho Nacional de Saúde - Pesquisa em Ciências Humanas e Sociais. 
As informações foram extraídas de um prontuário eletrônico, com ênfase na anamnese, investigação clinica, localização das lesões e suas descrições, classificação, forma clinica, exames complementares laboratoriais e histopatológicos, além do tratamento realizado e a evolução clinica do paciente. Esses dados, foram digitalizados sistematizados no programa Microsoft Word 2016® com posterior análise qualitativa e interpretação crítica. Por fim, os estudos utilizados para a discussão deste trabalho foram extraídos das bases de dados PUBMED, SCIELO, entre outras, obtidos por meio dos descritores "Isotretinoína" and "Tecido de Granulação Exuberante" and "Reação Adversa".

\section{RELATO DE CASO}

O paciente M.P.S, sexo masculino, 20 anos, estudante, natural de Santana dos Garrotes - Paraíba, realizou a procura do atendimento especializado em dermatologia, no final de setembro de 2017, com a queixa de "caroços" e "cascas" (SIC) em face há cerca de 20 dias.

$\mathrm{Na}$ história da doença atual, o paciente refere que apresentou um surto de acne no rosto há mais ou menos 6 meses e procurou um dermatologista para realizar o tratamento específico. Nesse período foi utilizado a isotretinoína oral como agente terapêutico, na dose de $40 \mathrm{mg}$ e com posologia de duas vezes ao dia $(1,14 \mathrm{mg} / \mathrm{kg} / \mathrm{dia})$, como tentativa de resolução da patologia apresentada. No entanto, as lesões em sua face não obtiveram melhora, e sim uma piora significativa com evolução em 20 dias para crostas e surgimento dessas, também, no dorso do paciente; o mesmo negou sintomas sistêmicos, como: febre ou perda ponderal; negou, também, comorbidades crônicas. Percebeu-se, ainda, um sentimento de vergonha extrema com a aparência do seu rosto. Ao exame fisico, foi evidenciado a presença de crostas espessas e dolorosas à palpação distribuidas por toda a face, exceto região orbital, nasal e preioral, e lobo de ambas orelhas com base eritematosa e descamativa (Figuras 1). A hiperemia contornava, também, a região perioral e região lateral da base do nariz. Ainda, as lesões presentes no paciente, 
não apresentavam saída de secreção purulenta. A conduta desse atendimento foi a suspensão da isotretinoína oral e a prescrição de antibiótico oral (Levofloxacino 500mg, 01 comprimido ao dia por 10 dias), um glicocorticóide oral (Prednisona 20 mg, 01 comprimido ao dia por 15 dias) e Óleo Mineral para a remoção das crostas de aplicação diária.

Em meados de outubro do referido ano, o paciente retornou ao ambulatório especializado para seguimento clínico de sua patologia. Ao exame físico da face, foi observado uma diminuição significativa, estimada em quarenta por cento, da área coberta pelas crostas, além de um aumento razoável da hiperemia presente na base dessas lesões e a ausência de descamação antes observada (Figura 2). A conduta deste atendimento foi a manutenção da terapia inicial por mais 15 dias.

Figura 1. Granulação crostosa exuberante - Admissão.

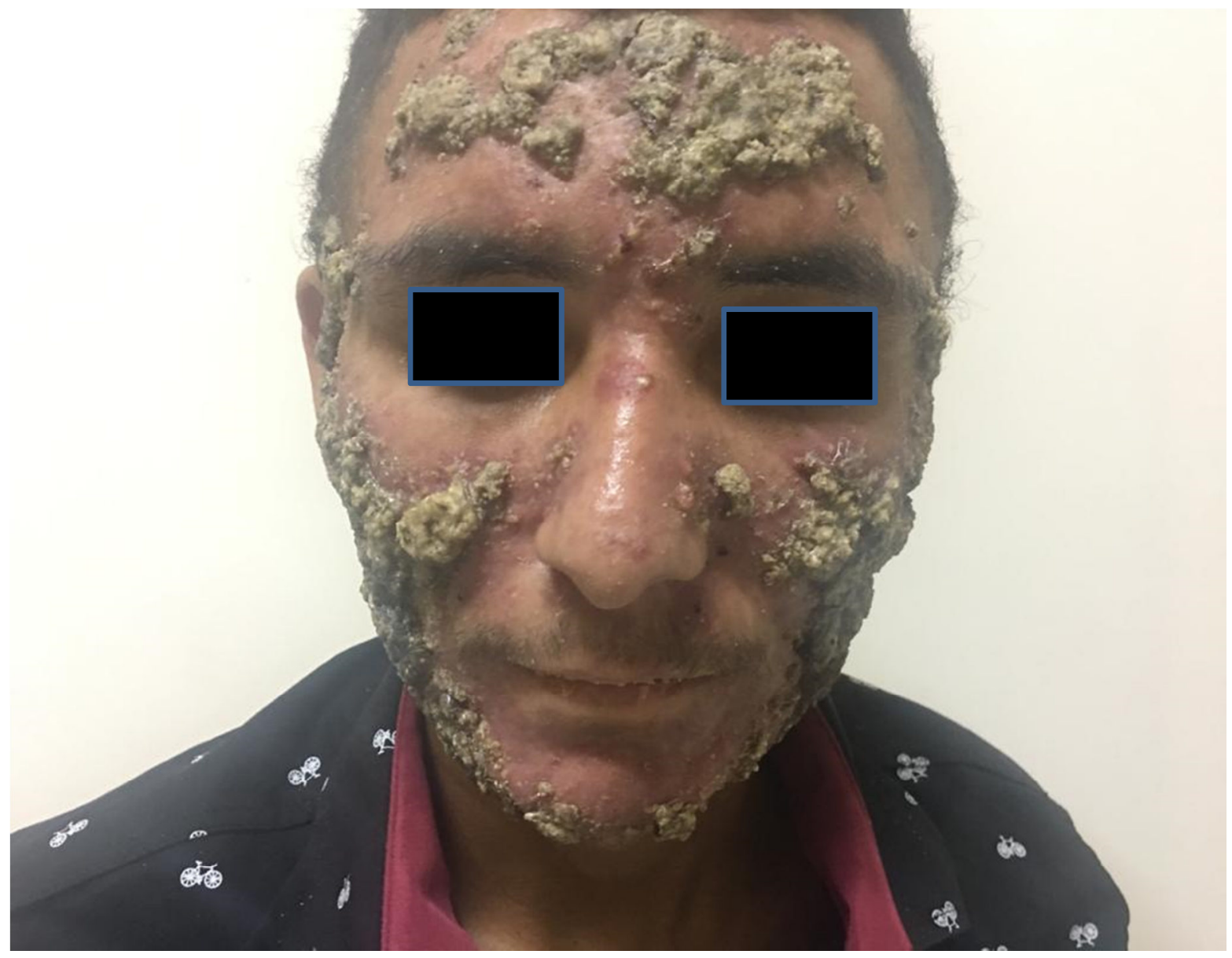

Fonte: Autoria própia. 
Figura 2. Granulação crostosa exuberante - evolução após 14 dias do tratamento inicial.

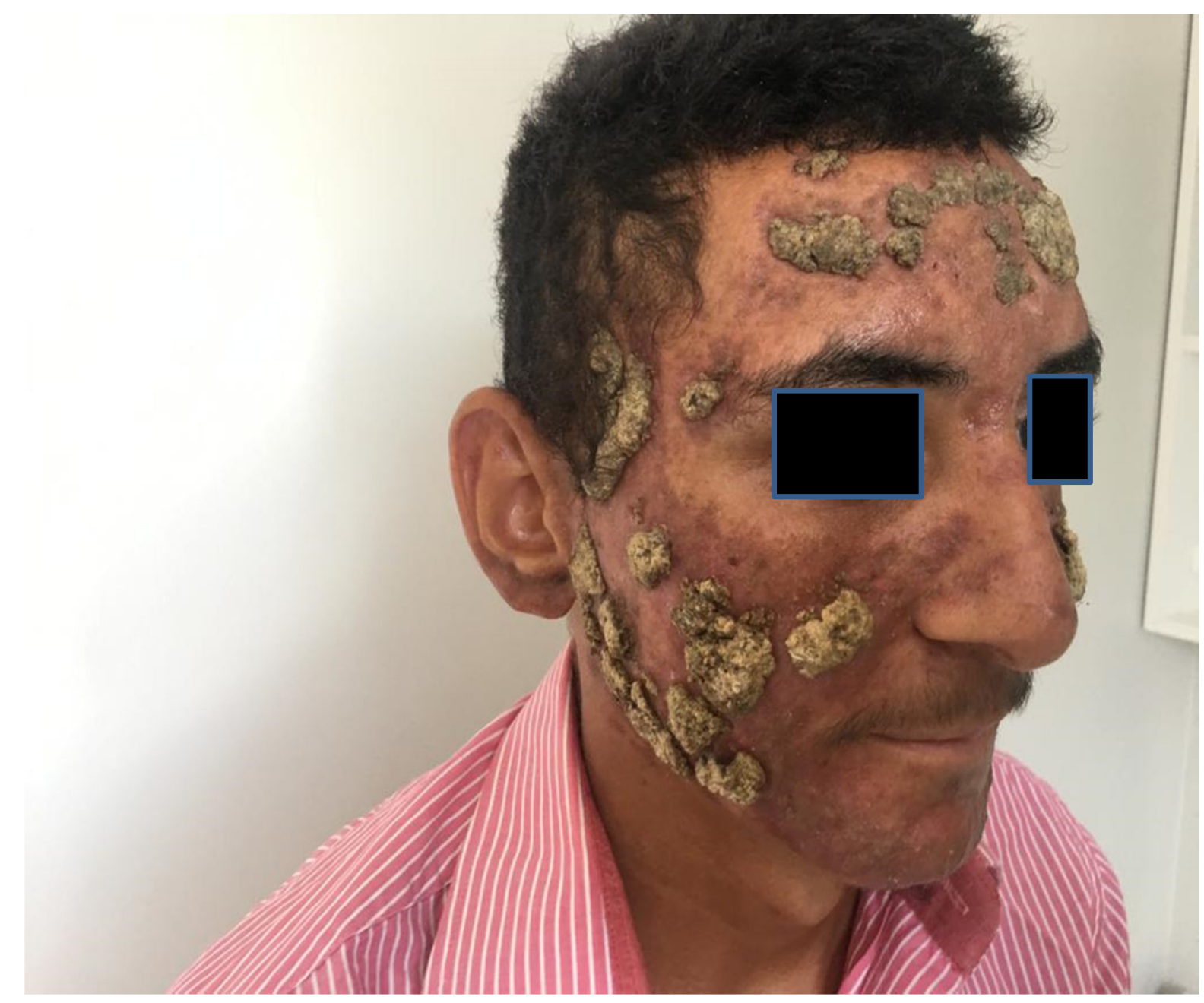

Fonte: Autoria própria.

No começo de novembro de 2017, o paciente compareceu a mais uma consulta para avaliação de suas lesões faciais. Ao exame físico, observou-se a presença de apenas quinze porcento do total de crostas antes identificadas, além da diminuição da espessura de grande parte das crostas restantes (Figura 3). O tratamento prescrito para o seguimento foi a manutenção do glicocorticóide (Prednisona $20 \mathrm{mg}, 01$ comprimido ao dia por 15 dias) e um antimicrobiano e antiinflamatório associados em uma pomada (Ácido Fusídico $20 \mathrm{mg} / \mathrm{g}+$ 
Betametasona $1 \mathrm{mg} / \mathrm{g}$, aplicação de uma camada fina no rosto de $12 / 12 \mathrm{~h}$ por 15 dias).

Figura 3. Granulação crostosa exuberante - evolução após 30 dias de tratamento.

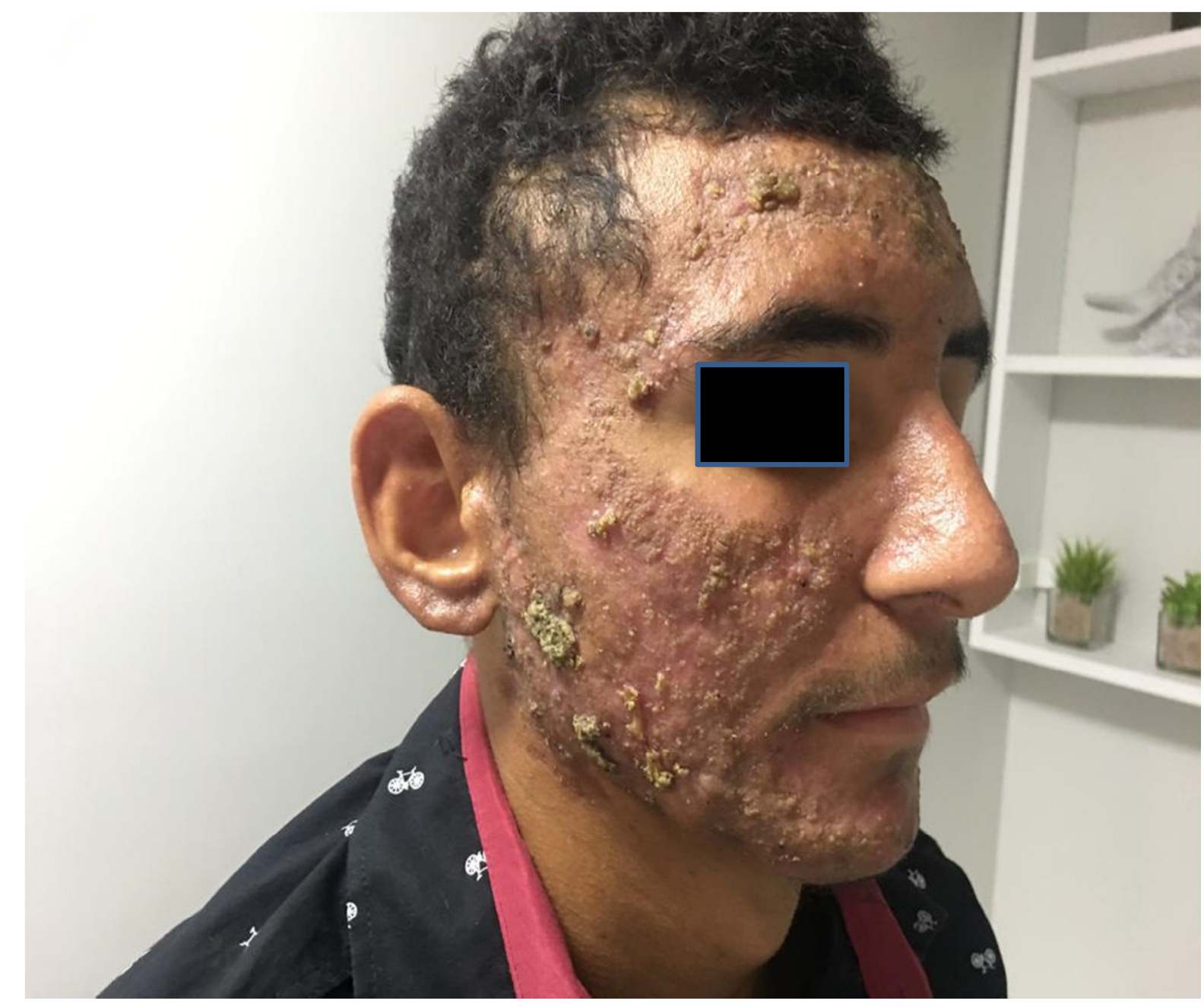

Fonte: Autoria própria.

O paciente retorna quatorze dias após a última consulta com a melhora total das lesões crotosas e redução da área abrangida pela hiperemia, tornando-a mais esparssa. Após a regressão das lesões crostosas, foi evidenciado a presença de várias cicatrizes pós-acne classificadas em Box Scar e Icepick distribuidas por toda a face do paciente (Figuras 4). O tratamento preconizado pelo especialista, nesse momento, foi a utilização de um gel bactericida (Clindamicina $10 \mathrm{mg} / \mathrm{g}+$ Peróxico de Benzoíla $50 \mathrm{mg} / \mathrm{g}$, aplicação de uma camada fina no rosto à noite). 
Figura 4. Granulação crostosa exuberante - evolução após 45 dias de tratamento.

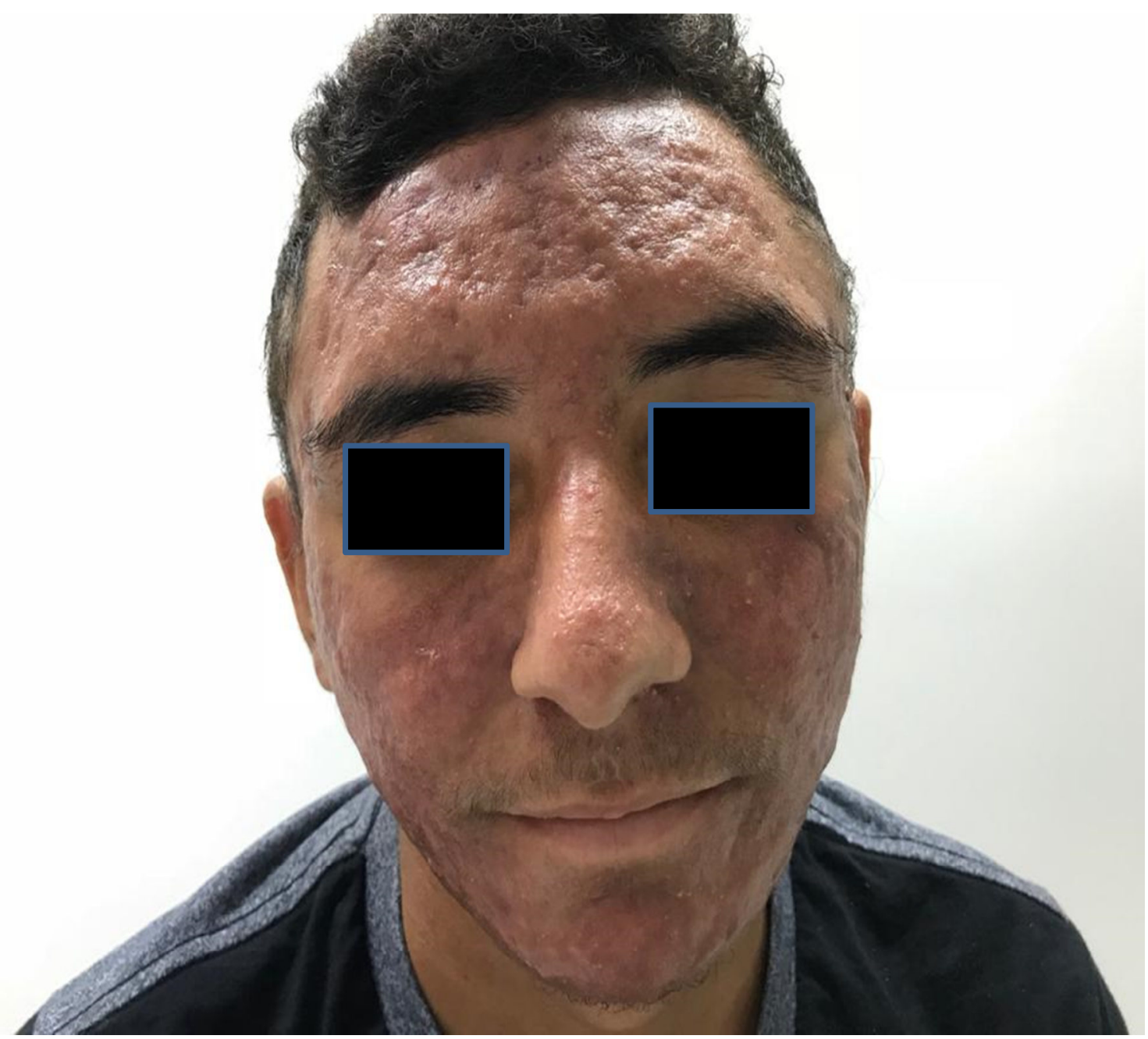

Fonte: Autoria própria.

No começo de fevereiro de 2018, o paciente é atendido para avalição dermatológica após último tratamento indicado. O resultado é contemplado no exame físico que demonstra melhora quase total das lesões de acne e, melhora da hiperemia na sua totalidade, restando apenas uma ou duas lesões de acne tipo II e as cicatrizes de acne aqui já relatadas. Foi identificado ainda, uma melhora importante do estado de humor e autoestima do paciente. A conduta foi mantida e orientado retorno em dois meses.

O paciente retorna ao ambulatório de dermatologia para a avaliação clínica solicitada evoluindo com a melhora do aspecto das cicatrizes de acnes, onde foi 
possível identificar uma diminuição leve da profundidade das mesmas. Além disso, o paciente encontra-se satisfeito com o resultado, com melhor estado de humor e autoestima comparado ao inicio do tratamento (Figura 5).

Figura 5. Granulação crostosa exuberante - evolução após 240 dias de tratamento.

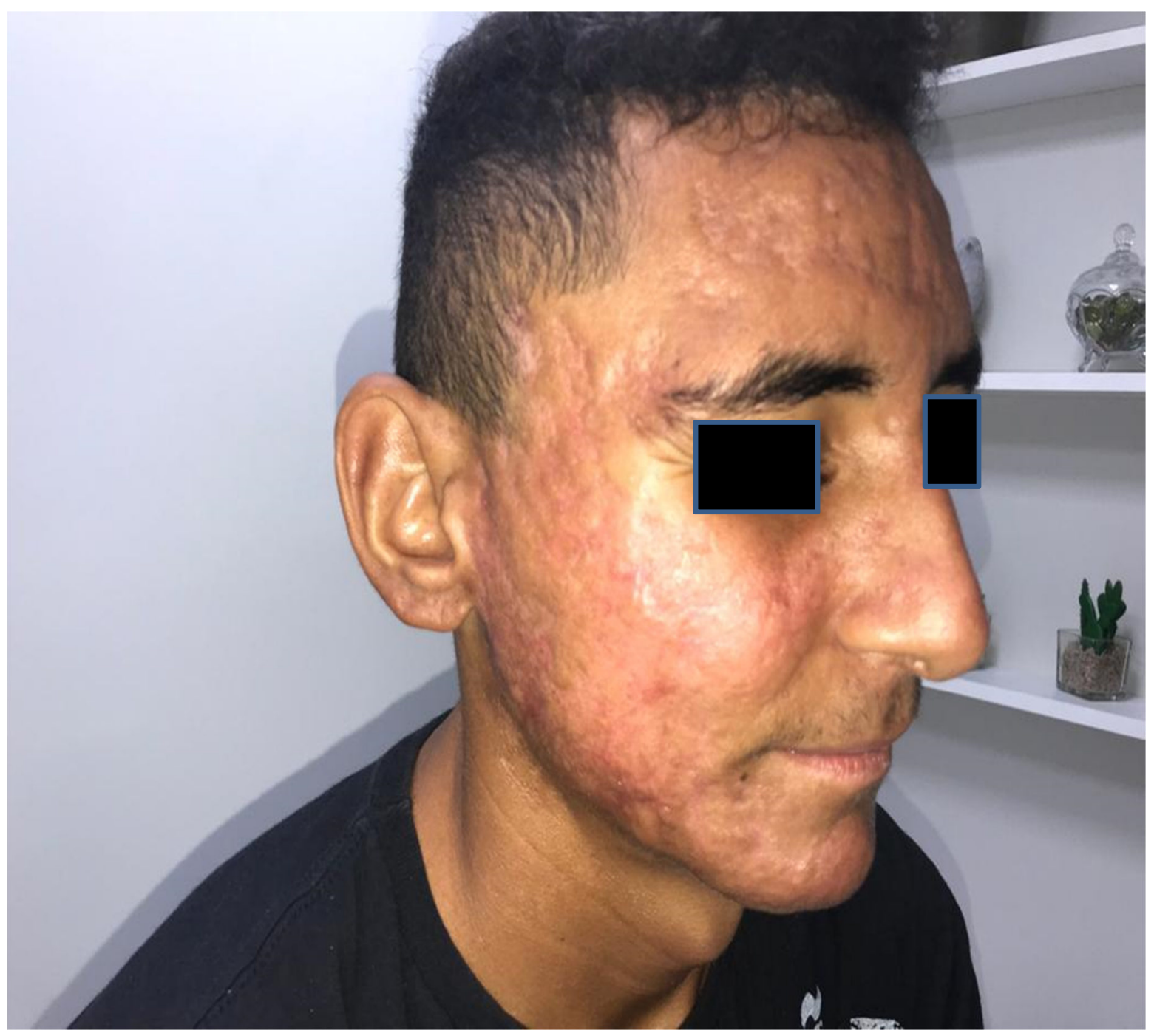

Fonte: Autoria própria. 


\section{DISCUSSÃO}

A acne é uma afecção cutânea que deve sempre ser tratada da forma mais precoce possível, independente da idade do paciente, tendo em vista interromper a progressão para cicatrizes com consequente repercussões sociais e psicológicas que podem acometer negativamente a qualidade de vida do paciente. Dessa forma, a instituição de tratamento eficaz se torna necessário e, dentre o arsenal terapêutico disponível, sabe-se que a isotretinoina oral é o único tratamento resolutivo dessa afecção. Porém, como todo medicamento, este possui alguns efeitos colaterias comuns como: hipertrigliceridemia, hipercolesterolemia, mialgias e artralgias e transaminases elevadas (SAMPAIO et al., 2008; BRITO et al., 2010).

No entanto, o paciente relatado neste caso, previamente hígido, apresentou um paraefeito raro durante o uso da isotretinoina que afetou diretamente sua autoestima e qualidade de vida, o surgimento do tecido de granulação exuberante após 20 dias do inicio do tratamento. Assim, pode-se considerar um surgimento precoce desse efeito adverso, tendo em vista os relatos encontrados na literatura que abordaram o surgimento dessas lesões entre duas semanas e 6 meses de tratamento. Outro fato que merece atenção, é o relato desse efeito apenas em pacientes do sexo masculino, sugerindo a implicância dos esteróides sexuais na gênese ou manutenção do processo de formação do granuloma crostoso (HAGLER et al., 1992; FIGUEIRAS et al., 2016).

A fisiopatologia desse efeito colateral ainda não é bem compreendida, porém, alguns autores apontam o efeito do excesso de vitamina A promovida pela isotretinoina ou outros retinoides orais, como o entretinato. Esse efeito induz a síntese aumentada de mucopolissacarídeo no tecido de granulação em alguma etapa do processo de cicatrização. Além disso, a isotretinoina ao diminuir adesão dos desmossomas e o número de tonofilamentos, acumulando material amorfo dentro dos queratinócitos e dilatando os vasos dérmicos, propricia o retardo da reepitelialização e leva a uma fragilidade na derme que culmina no aparecimento do tecido de granulação exuberante. Outro processo aventado, seria uma reação 
imunológica exacerbada contra os antígenos da Propionibacterium acnes liberados em grande quantidade após o início da terapia com o retinoide oral (CAMPBELL et al., 1983; ROBERTSON; NUBIAK; GOMEZ, 1984; LI et al., 2018).

Figueiras et al. (2016) e Sampaio et al. (2008) apontam de que o surgimento da granulação crostosa exuberante não possui relação direta com a dose de retinóide oral diária ou cumulativa tendo em vista a dose usual segura de 0,5$2 \mathrm{mg} / \mathrm{kg} / \mathrm{dia}$. Isso pode ser observado nos estudos encontrados em que seus pacientes apresentaram esse efeito colateral mesmo com doses variando de 0,6-2,6 $\mathrm{mg} / \mathrm{kg} /$ dia e exames laboratoriais de rotina normais. A dose utilizada pelo paciente desse estudo foi de $1,14 \mathrm{mg} / \mathrm{kg} / \mathrm{dia}$, um pouco maior que a dose mínima diária encontrada (ROBERTSON; NUBIAK; GOMEZ, 1984; FRIEDLANDER, 1998).

O tratamento utilizado no paciente em questão foi a antibioticoterapia e a corticoterapia oral de ataque com o auxílio de um emoliente químico para facilitar a retirada das crostas; seguimento com antimicrobianos tópicos e a manutenção da corticorapia oral; e finalização com gel bactericida, ressaltando aqui a melhora progressiva em cada etapa do tratamento que durou cerca de 8 meses e ao seu final, o paciente foi considerado totalmente tratado da sua patologia. Nesse sentido, é importante ressaltar o papel do glicocorticoide na regressão da doença, tendo em vista, o seu efeito no crescimento do estroma fibroso com diminuição na proliferação dos fibroblastos e inibição da síntese de mucopolissacarídeos e deposição de colágenos, além de um efeito vasoconstrictor. Assim, o uso da corticoterapia atua diretamente no processo de fisiopatologia sugerido pelos autores e com bons resultados clínicos (MILLER; ROSS; MARTIN, 1985).

Nesse interim, foram encontrados várias formas de tratamento para esta patologia com resultados variáveis para cada paciente. O ácido tricloroacético nas concentrações de 35 a 70\% de aplicação semanal é uma opção útil para o controle da lesão, assim como, a curetagem e a cauterização elétrica ou com nitrato de prata. Além disso, a redução em $50 \%$ da dose utilizada de isotretinoina oral foi utilizada por alguns autores na tentativa de manter o tratamento com retinoide oral, obtendo baixa taxa de sucesso terapeutico quando comparados aqueles que suspenderam a isotretinoina. Por fim, a utilização da corticoterapia tópica de alta potência mostrou bons resultados na regressão do tecido de granulação, mesmo que a médio prazo, 
podendo esta ser potencializada com a técnica de oclusão (CAMPBELL et al., 1983; MILLER; ROSS; MARTIN, 1985; AZULAY et al., 1985; LLUIS et al., 1986; SAMPAIO et al., 2008).

Por fim, Friedlander (1998) sugere o uso plausível de corticoesteróide sistêmico antes do inicio ou durante o tratamento com retinóide oral naqueles pacientes com acne grau IV, independente dos sintomas sistêmicos.

\section{CONCLUSÃO}

O paciente retratado no caso clínico em questão apresentava acne nódulocística a qual foi tratada inicialmente com isotretinoina oral com progressão para um efeito adverso raro, o tecido de granulação exuberante. Assim, foi realizada a suspensão da isotretinoina oral $\mathrm{e}$ inicio de um tratamento de ataque com corticoterapia e antibioticoterapia por via oral e manutenção por via tópica até a resolução completa das lesões que ocorreu em 8 meses.

Dessa forma, tendo em vista a precariedade de estudos a cerca do assunto abordado, se faz necessário novos estudos com pacientes que desenvolveram essa patologia, auxiliando os profissionais médicos para a escolha do melhor tratamento segundo nível de evidência disponível. Com a melhor compreensão, é possível que sejam desenvolvidas e direcionadas ações específicas para o manejo dessa enfermidade.

\section{REFERÊNCIAS BIBLIOGRÁFICAS}

ARAGÃO, J. Introdução aos estudos quantitativos utilizados em pesquisas científicas. Revista Práxis, v. $3, \quad$ n. $\quad 6, \quad$ p. 59-62, 2011. Disponível em: <http://revistas.unifoa.edu.br/index.php/praxis/article/view/566>. Acesso em: 29 maio 2020.

AZULAY, D. R. et al. Tecido de granulação exuberante: Efeito colateral da terapêutica com isotretinoina. Anais Brasileiros de Dermatologia, v. 60, n. 4, p. 179-182, 1985.

BIESKI, G. L. Riscos e benefícios do uso do medicamento isotretinoína para o tratamento da acne. FACIDER Revista Científica, v. 1, n. 09, p. 1-15, 2016. 
BRITO, Maria de Fátima de Medeiros et al. Avaliação dos efeitos adversos clínicos e alterações laboratoriais em pacientes com acne vulgar tratados com isotretinoína oral. Anais Brasileiros de Dermatologia, v. 85, n. 3, p. 331-337, 2010.

CAMPBELL, J. $\mathrm{P}$ et al. Retinoid therapy is associated with excess granulation tissue responses. Journal of the American Academy of Dermatology, v. 9, n.1, p. 708-713, 1983.

FEILY, A. et al. The effect of low-dose isotretinoin therapy on serum androgen levels in women with acne vulgaris. International Journal Of Women's Dermatology, v. 6, n. 2, p. 102-104, 2020.

FIGUEIRAS, Daniela de Almeida et al. Paronychia and granulation tissue formation during treatment with isotretinoin. Anais Brasileiros de Dermatologia, [S.L.], v. 91, n. 2, p. 223-225, abr. 2016.

FRIEDLANDER, Sheila Fallon. Effective treatment of acne fulminans-associated granulation tissue with the pulsed dye laser. Pediatric Dermatology, v. 15, n. 5, p. 396-398, 1998.

HAGLER, JOSEPH et al. Facial pyogenic granuloma-like lesions under Isotretinoin therapy. International Journal of Dermatology, v. 31, n .3, 1992.

LI, Alvin W. et al. Isotretinoin-induced acne fulminans without systemic symptoms with concurrent exuberant granulation tissue. Pediatric Dermatology, [S.L.], v. 35, n. 2, p. 257-258, jan. 2018.

LLUIS, Puig et al. Granulation Tissue Proliferation During Isotretinoin Treatment. International Journal of Dermatology, v.25, n. 3, p. 191-193, 1986.

MILLER, R. A. W.; ROSS, J. B.; MARTIN, J. Journal of the American Academy of Dermatology, v. 12, n. 5, p. 888-889, 1985.

OLIVEIRA, Aline Tavares de et al. Relato de caso na prática médica. In: SOUSA, Milena Nunes Alves de; SANTOS, Everson Vagner de Lucena (Org.). Medicina e pesquisa: Um elo possível. Curitiba: Prismas, 2016. p. 153-160.

RIVITTI, E. A. Dermatologia. São Paulo: Artes Médicas; 2014.

ROBERTSON, D. B.; NUBIAK, E.; GOMEZ, E. C. Excess granulation tissue responses associated with isotretinoin therapy. British Journal of Dermatology, v. 3, n. 1, p.689-694, 1984.

SAMPAIO, Sebastião de Almeida Prado et al. Experiência de 65 anos no tratamento da acne e de 26 anos com isotretinoína oral. Anais Brasileiros de Dermatologia, [S.L.], v. 83, n. 4, p. 361-367, ago. 2008.

SILVA JÚNIOR, E. D. da. Isotretinoína no tratamento da acne: riscos $\mathrm{x}$ benefícios. Revista Brasileira de Farmacologia, v. 90, n. 3, p. 189-89, 2009. 